$\begin{array}{cl}\text { Türkiye Tarımsal Araştırmalar Dergisi } & \text { Turk J Agric Res } \\ \text { dergipark.gov.tr/tutad } & \text { 2017, 4(2): 163-170 } \\ \text { O TüTAD } & \text { ISSN: 2148-2306 } \\ \text { e-ISSN: 2528-858X } & \text { doi: 10.19159/tutad.293630 }\end{array}$

\title{
Topraksız Kültür Sisteminde Sofralık Üzüm Yetiştiriciliğinin Araştırılması
}

\author{
Semih TANGOLAR ${ }^{1}$, Serpil TANGOLAR ${ }^{*}$, Ayfer ALKAN TORUN², \\ Güzin TARIM', Melike ADA ${ }^{1}$ \\ ${ }^{l}$ Çukurova Üniversitesi, Ziraat Fakültesi, Bahçe Bitkileri Bölümü, Adana, TÜRKIYYE \\ ${ }^{2}$ Çukurova Üniversitesi, Ziraat Fakültesi, Toprak Bilimi ve Bitki Besleme Bölümü, Adana, TÜRKIYE
}

\begin{abstract}
Geliş Tarihi/Receive d: 22.02 .2017
Kabul Tarihi/Accepted: 04.05.2017

*Sorumlu Yazar/Corresponding Author: stangolar@cu.edu.tr

Özet: Bu çalışma, sofralık üzüm yetiştirmede topraksız kültür tekniğinin uygulanabilirliğini araştırmak amacıyla planlanmıştır. Çalışmada, Yalova İncisi, Trakya İlkeren ve Prima çeşitleri plastik örtü altında topraksız kültür koşullarında Cocopeat, Torf:Perlit $(1: 2)$ ortamlarında, değiştirilmiş Hoagland çözeltisi kullanılarak yetiştirilmiştir. Çalışmanın birinci yılında (2014 yılı), sürgün uzunluğu, boğum sayısı ve sürgün çapı; ikinci ve üçüncü yıllarında ise uygulamaların çeşitlerde fenolojik özellikler, üzüm verimi ile salkım ağıllı̆ı, 100 tane ağırlığı, şıra özellikleri ve yaprakların mineral besin maddesi içerikleri üzerine etkilerine bakılmıştır. Yalnızca bir sürgünün büyütüldüğü birinci gelişme döneminde; en yüksek sürgün uzunluğu değeri $(182.5 \mathrm{~cm})$ Trakya İlkeren çeşidinde, en geniş çap değeri $(6.42 \mathrm{~mm})$ de Cocopeat ortamında saptanmıştır. En yüksek üzüm verimleri, ikinci ve üçüncü ürün yıllarında (2015 ve 2016) Prima (sırasılyla 6731 ve $4204 \mathrm{~g}^{\text {omca }}{ }^{-1}$ ) ve Trakya İlkeren (sırasıyla 6577 ve $3941 \mathrm{~g} \mathrm{omca}^{-1}$ ) çeşidinde saptanmıștır. Her iki yılda da en yükssek salkım ağırlı̆̆ değerleri Trakya İlkeren (sırasıyla, 506.3 ve 394.1 g) çeşidinden elde edilmiştir. Verim ve salkım ağırlığı ile gövde çapı bakımından Torf:Perlit $(1: 2)$ ortamı, Cocopeat ortamından daha yüksek değerler vermiştir. Bu ve incelenen diğer özelliklerden elde edilen sonuçlar, topraksız kültür ortamında yetișen Prima ve Trakya İlkeren çeșitlerinin açıkta ve geleneksel koșullarda yetişenlerden daha yüksek verim ve yeterli kaliteye ulaşabileceğini göstermiştir. Ayrıca, araştırma koşullarında, denemeye alınan iki yetiştirme ortamının da önerilebileceği sonucuna varılmıştır.
\end{abstract}

Anahtar Kelimeler: Asma, örtüaltı yetiştiricilik, yetiştirme ortamı, besin solüsyonu, torf

\section{Evaluation of Table Grape Cultivation in Soilless Culture System}

\begin{abstract}
This study was planned to investigate the applicability of soilless culture technique for table grape cultivation. In the study, Yalova incisi, Trakya İlkeren and Prima cultivars were grown using Cocopeat and Torf:Perlite $(1: 2)$ medium wit h modified Hoagland solution under soilless culture conditions under plastic cover. In the first year of the work (2014), sho ot length, number of nodes and shoot diameter; in the second and third years, the effects of the applications on phenological characteristics, grape yield, cluster and 100 berry weight, must characteristics and mineral nutrient level of the leaves were examined. During the first development period, when only one shoot grows, the longest shoot length $(182.5 \mathrm{~cm})$ was found in the Trakya İlkeren and the largest diameter $(6.42 \mathrm{~mm})$ was found in the Cocopeat medium. In the second and third crop years (2015 and 2016), the highest grape yields were observed in Prima (6731 and $4204 \mathrm{~g} \mathrm{vine}^{-1}$, respectively) and Trakya

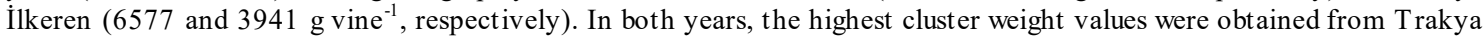
İlkeren (506.3 and $394.1 \mathrm{~g}$, respectively). In terms of yield, cluster weight and trunk diameter, Torf: Perlite (1:2) medium gave higher values than Cocopeat medium. The results obtained from these and other traits have shown that Prima and Trakya İlkeren cultivars grown in the soilless culture medium can achieve higher yield and sufficient qualities than those grown in open and conventional conditions. Additionally, in the research con ditions, both growth medium that have been tested can be suggested for table grape cultivation in soilless culture.
\end{abstract}

Keywords: Grapevine, protected cultivation, growth medium, nutrient solution, peat 


\section{Giriş}

Herhangi bir ekolojide daha erken ürün elde etmek amaciyla kullanılan en önemli tekniklerden birisi plastik veya cam örtü altında yetiştiriciliktir. Akdeniz Bölgesi iklim koşullarının sebzecilikte olduğu gibi, meyvecilik ve bağcılıkta da bu bakımdan uygun koşullara sahip olduğu bilinmektedir. Bağcılıkta normal yetiştiricilik koşulları altında asmaların tamamen veya kısmen plastik ile örtülmesiyle isıtma yapmaksızın üzüm olgunluğunun 30-45 gün kadar erkene alındığ1 belirlenmiştir (Uzun ve Özbaş, 1995; Ergenoğlu ve ark., 1999a ve 1999b; Polat ve Uzun, 2007; Kamiloğlu ve ark., 2011; Tangolar, 2011). Ancak bu yetiştiricilik şeklinde de, açıkta üzüm yetiştiriciliğinde var olan sorunlarla mücadele gerekmektedir. $\mathrm{Bu}$ sorunlar içinde en önemlisi filoksera ve özellikle sulanan bağlarda etkili nematod zararına karşı Amerikan Asma anaçlarının kullanılmasıdır.

Günümüzde yaygın olarak sebze ve süs bitkileri yetiştiriciliğinde kullanılan topraksız kültür tekniğinin (Gül, 2012), birçok avantajları yanında sofralık üzüm yetiştiriciliğinde özellikle anaçlardan kaynaklanan sorunların üstesinden gelmede, asma beslenmesinin daha kontrollü yapılmas1 ve sulama suyunun daha etkin kullanılması ile verim ve kalitenin kontrol edilmesinde önemli bir araç olabileceği düşünülmektedir. $\mathrm{Bu}$ tekniğin örtüaltında sofralık üzüm yetiştirme amacıyla başarıyla kullanılabileceği değişik araştırmalarda (Polat ve ark., 2003; Buttaro ve ark., 2012; Di Lorenzo ve ark., 2005, 2012 ve 2013) gösterilmiştir. Gül (2012) ve Varış (2012) da, topraksız kültür yetiştiricilikte, uygun yöntemler ile ortamların kullanılmas1 ve bitkilerin iyi beslenmesi durumunda, toprakta yapılan yetiştiriciliğe göre daha erkenci ve daha yüksek verim ve kaliteli ürün elde edilebileceğini, bu yetiştiricilik ile çevre kirliliğinin azaltılmasına da katkıda bulunulabileceğini bildirmiştir.

Buttaro ve ark. (2012), bu teknik ile mevcut sofralı üzüm üretiminde karşılaşılan bazı sorunların aşılmasının mümkün olabileceğini belirtmiştir. Araştırıcılara göre topraksız kültür, insan işgücünü azaltır ve patojenlerden ari bir ortam yaratırken; aynı zamanda bitki büyümesini iyileştirmekte, ürün verim ve kalitesini artırmaktadır. Di Lorenzo ve ark. (2012) ile Buttaro ve ark. (2012) topraksız kültürde sofralık üzüm yetiştiriciliğinin başlıca avantajlarının; 1) Aşılamaya ve aşılı asma kullanımına gerek duyulmaması, 2) Toprağın olmadığı alanlarda kullanılabilmesi, 3) Tuzluluk veya kireçlilik benzeri toprak kökenli sorunların dışlanması,
4) Toprak kökenli patojenlerle bulaşmış topraklarda uygulanabilmesi, 5) Toprak kökenli patojen birikiminin olmaması, 6) Bir yılda çoklu ürün alma olanağının bulunmas1, 7) Pazara bağlı üretimin mümkün olabilmesi, 8) Pazarlanabilir miktar ve kalitede ürün elde edilebilmesi, 9) Birim alandan yüksek verim alınabilmesi, 10) Ürün olgunluğu ve hasadının erken veya geç yapılabilmesi, 11) Hızlı çeşit değişimine olanak vermesi, 12) Pestisit uygulamaları ve buna bağh işgücü gereksinimini azaltmas1, 13) Ürün kalitesini iyileştirmesi, 14) Geliri etkili şekilde arttırması, olduğunu bildirmektedirler.

Sofralık üzüm yetiştiriciliğinde topraksız kültür tekniğinin kullanıldı $\breve{g}_{1}$ sınırlı sayıda araştırmaların yapıldığı görülmektedir. Bunların bazıları, Sicilya, Apulia-İtalya'da (Di Lorenzo ve ark., 2012; Buttaro ve ark., 2012) ve ülkemizde de, Polat ve ark. (2003) tarafindan Antalya'da yapılanlardır. Meyve ağaçlarında da benzer şekilde sınırlı sayıda çalışmanın olduğu bildirilmektedir (Buttaro ve ark., 2012).

Yapılan bu çalışmanın amacı, sofralık üzüm yetiştiriciliği potansiyeli yüksek olan Akdeniz Bölgesi'nin örtüaltı tarımına uygun kesimleri için sürdürülebilir, kalite ve verim anlamında daha rekabetçi alternatif bir yetiştirme sisteminin geliştirilmesine ilişkin bir modelin denenmesidir.

\section{Materyal ve Yöntem}

$\mathrm{Bu}$ çalışma; Çukurova Üniversitesi, Ziraat Fakültesi, Araştırma ve Uygulama Bağı'nda topraksız kültür sisteminde 2014-2016 y1lları arasında olmak üzere üç yıl süreyle yürütülmüştür.

Çalışmada bitki materyali olarak; Trakya İlkeren, Yalova İncisi ve Prima üzüm (Vitis vinifera L.) çeşitleri ile yetiştirme ortamı olarak Cocopeat (Hindistan cevizi torfu) ve Torf-Perlit (1:2) karışımı kullanılmıştır.

Çalışmanın 1. yılında, kullanılacak bitki materyalinin elde edilmesi için Şubat 2014 itibariyle budama zamanında asmanın bir yaşlı, sağlıklı ve iyi odunlaşmış dallarından 3-5 gözlü çelikler hazırlanmış ve bunlar perlit ortamında, gerektiğinde sadece su verilerek köklendirilmiştir. Yaklaşı 45 günlük bir köklendirme süresi sonunda köklü bitkiler, her birine birer bitki olacak şekilde içinde Torf:Perlit ve Cocopeat olmak üzere 2 farklı yetiştirme ortamı bulunan 32 litrelik saksılara 16 Nisan 2014 tarihinde dikilmiştir.

Fidanlar, ilk y1l, belirtilen ortamlarda 9-10 ay boyunca sera dışında tutularak yetiştirilmiştir. Bitkilerde yaprak dökümünü takiben, Ocak ay1 sonunda her bitkide 1-1.5 m uzunlukla bir dal bırakacak şekilde budama yapılmıştır. Daha sonra 
saksılar sera içine, $0.75 \mathrm{~m}$ sıra üzeri ve $1.50 \mathrm{~m}$ sıra arası mesafelerle ve siyah polietilen ile örtülü düz bir zemine yerleştirilmiştir.

Deneme, her birinin taban alan $100 \mathrm{~m}^{2}$ olan yandan havalandırmalı, yüksekliği $2 \mathrm{~m}$, genişliği 3 $\mathrm{m}$ ve uzunluğu $33 \mathrm{~m}$ olan iki plastik serada yürütülmüştür. Çalışmada, bazı araştırmalardan (Hoagland ve Arnon, 1950; Buttaro ve ark., 2012; Di Lorenzo ve ark., 2013) yararlanılarak modifiye edilmiş Hoagland besin çözeltisi kullanılmıştır. Kullanılan besin çözeltisinin konsantrasyonu; 100 ppm azot $(\mathrm{N})\left(\mathrm{NH}_{4} \mathrm{NO}_{3}\right.$ formunda), $20 \mathrm{ppm}$ fosfor (P) $\left(\mathrm{H}_{3} \mathrm{PO}_{4}\right.$ formunda), $150 \mathrm{ppm}$ potasyum $(\mathrm{K})$ $\left(\mathrm{KSO}_{4}\right.$ veya $\mathrm{KNO}_{3}$ formunda), $20 \mathrm{ppm}$ magnezyum (Mg), $\left(\mathrm{MgSO}_{4}\right.$ formunda), $15 \mathrm{ppm}$ kükürt (S) (Sülfat bileşikleri formunda), $5 \mathrm{ppm}$ demir ( $\mathrm{Fe})(\mathrm{Fe}-\mathrm{EDDHA}$ formunda), $1 \mathrm{ppm}$ çinko (Zn) $\left(\mathrm{ZnSO}_{4} .7 \mathrm{H}_{2} \mathrm{O}\right.$ formunda), $3 \mathrm{ppm}$ mangan (Mn) ( $\mathrm{MnSO}_{4}$ formunda), $0.2 \mathrm{ppm}$ bakır $(\mathrm{Cu})$ $\left(\mathrm{CuSO}_{4} .5 \mathrm{H}_{2} \mathrm{O}\right.$ formunda) $0.4 \mathrm{ppm}$ bor $(\mathrm{B})\left(\mathrm{H}_{3} \mathrm{BO}_{3}\right.$ formunda) ve $0.05 \mathrm{ppm}$ molibden (Mo) $\left(\mathrm{NH}_{4} \mathrm{Mo}_{7} \mathrm{O}_{24}\right.$. $4 \mathrm{H}_{2} \mathrm{O}$ formunda) olarak düzenlenmiştir.

Makro, mikro ve Fe solüsyonları ayrı ayrı hazırlanmıştır. Asmalar her hafta düzenli olarak bu üç farklı besin çözeltisi karışımı ile gübrelenmiştir. Çalışmada, Buttaro ve ark. (2012) ile Di Lorenzo ve ark. (2013)'nın makaleleri ve yazışmalarla kendilerinden aldığımız görüşleri ve yaptığımız ön denemeler dikkate alınarak, göz uyanmas1-yaprak dökümü arasındaki dönemde bitki başına 1-3 L gün ${ }^{-1}$ su uygulaması yapılmıştır. Çalışmada sulama suyu olarak kullanılan çeşme suyunun $\mathrm{pH}$ değerinin 7.86; elektriksel iletkenlik (EC) değerinin 0.698 olduğu belirlenmiştir.

Birinci yllda, dikimi takiben su ve besin solüsyonu uygulanmasına da başlanmıştır. Eylül ayına kadar sürdürülen besin solüsyonu verme uygulamasında makro besin çözeltisinden $10 \mathrm{~mL}$, mikro besin çözeltisinden ise $5 \mathrm{~mL}$ verilmiştir. İkinci ve üçüncü yılda ise asma gözleri uyanmaya başladığında besin çözeltisi verilmeye başlanmış ve olgunluğa kadarki sürede bitki başına $15 \mathrm{~mL}$ makro, $7.5 \mathrm{~mL}$ mikro besin çözeltisi verilmiştir. Olgunluktan Eylül ayına kadarki sürede bitki başına $10 \mathrm{~mL}$ makro, $5 \mathrm{~mL}$ mikro besin çözeltisi uygulanmıştır.

Uygulamaların karşılaştırılmasında aşağıda belirtilen özellikler incelenmiştir.

Denemenin 1. yılında tüm çeşit ve uygulamalarda 02.07.2014 tarihinde bitkilerin sürgün uzunluğu (cm), boğum sayısı (adet) ve gövde çap1 (mm) ölçülmüştür.

Denemenin 2. ve 3. yılında; fenolojik gözlemlerden; uyanma, tam çiçeklenme ve ben düşme ile derim tarihleri kaydedilmiştir. Ayrıca, üzüm verimi $\left(\mathrm{g}\right.$ omca $\left.^{-1}\right)$, salkım ağırlı̆̆1 $(\mathrm{g}), 100$ tane ağırlığı (g), suda çözünebilir kuru madde (SÇKM, \%), titre edilebilir asitlik (g 100 $\mathrm{mL}^{-1}$ şıra), $\mathrm{pH}$ ve olgunluk indisi özellikleri incelenmiştir. Uygulamaların yaprakların besin maddesi içeriklerine etkisinin görülebilmesi amaciyla ben düşme zamanında alınan tam yaprak örneklerinde (Ecevit ve Kismalı, 1984; Kovancı ve ark., 1984; Çelik ve ark., 1998; Çelik, 2011) makro (N, P, K, $\mathrm{Mg}$ ) ve mikro (Fe, $\mathrm{Zn}, \mathrm{Mn}$ ) besin element düzeylerine bakılmıştır. Azot, Kjeldahl (Lees, 1971; Kacar, 1995), fosfor Barton (1948) yöntemine; $\mathrm{K}, \mathrm{Mg}, \mathrm{Mn}, \mathrm{Fe}$ ve $\mathrm{Zn}$ miktarları ise Chapman ve Pratt (1961) ve Kacar (1995)'a göre Atomik Absorbsiyon spektrofotometresi kullanılarak saptanmıştır.

Deneme faktöriyel tesadüf blokları deneme desenine göre üç tekrarlı olarak planlanmıştır. Parsel büyüklüğü her uygulama ve yineleme için 5 asma olarak alınmıştır. Elde edilen verilere JMP istatistik programı kullanılarak varyans analizi uygulanmış ve farklı grupların saptanmasında LSD testinden yararlanılmıştır.

\section{Bulgular ve Tartış ma}

Topraksız kültür üzüm yetiştiriciliğinde çeşit ve ortamların fenolojik tarihler üzerine etkisine ilişkin bulgular Tablo 1'de sunulmuştur. Araştırmada, 2015 yılında uyanma en erken Trakya İlkeren çeşidinde ve 28 Şubat'ta olmuş, Yalova İncisi'nde 1 Mart tarihinde ve 6 Mart'ta da Prima çeşidinde gerçekleşmiştir. Çalışmanın 2016 yılında ise, Trakya İlkeren ilk uyanan çeşit olmuş, bunu Yalova İncisi ve Prima çeşidi takip etmiştir. Tam çiçeklenme 2015 ve 2016 yıllarında sırasıyla 5 Nisan ve 8 Nisan'da Trakya İlkeren çeşidinde; 7 Nisan ve 10 Nisan'da Yalova İncisi'nde; 11 Nisan ve 8 Nisan'da Prima çeşidinde gözlenmiştir. Ben düşme, üç çeşitte de 2015 yılında 2-3 Haziran'da gerçekleşmiştir. Çalışmada 2016 yılında ise, ben düşme 19-21 Mayıs tarihlerinde gözlenmiştir. Derimler ise 2015 yılında 25 Haziran'da 2016 yılında 14 Haziran'da gerçekleşmiştir (Tablo 1).

Trakya İlkeren, Yalova İncisi ve Prima üzüm çeşidinin, Cocopeat ve Torf:Perlit (1:2) ortamında yetişen bitkilerinde denemenin birinci yılında (2014) 2 Temmuz tarihinde yapılan ölçüm değerlerine göre (Tablo 2); sürgün uzunluğu en fazla olan çeşit Trakya İlkeren $(182.5 \mathrm{~cm})$ olmuş, bunu is tatistiki olarak aynı grupta yer alan Yalova İncisi $(139.6 \mathrm{~cm})$ ve Prima $(165.1 \mathrm{~cm})$ çeşidi takip etmiş̧tir. Boğum sayısı bakımından en yüksek değerleri istatistiksel olarak aynı grupta yer alan Prima (36.70 adet) ve Trakya İlkeren (36.30 adet) çeşidi vermiştir. Gövde çapı bakımından, çeşitler 
Tablo 1. Bazı erkenci üzüm çeşitlerinin fenolojileri üzerine farklı ortamların etkisi (2015 ve 2016 yılı) (gün/ay)

\begin{tabular}{|c|c|c|c|c|c|c|c|c|c|}
\hline \multirow{2}{*}{ Çeşit } & \multirow{2}{*}{ Ortam } & \multicolumn{2}{|c|}{ Uyanma } & \multicolumn{2}{|c|}{ Tam çiçek } & \multicolumn{2}{|c|}{ Ben düşme } & \multicolumn{2}{|c|}{ Derim } \\
\hline & & 2015 & 2016 & 2015 & 2016 & 2015 & 2016 & 2015 & 2016 \\
\hline \multirow{3}{*}{ Trakya İlkeren } & Cocopeat & $01 / 03$ & $01 / 03$ & $07 / 04$ & $08 / 04$ & $02 / 06$ & $20 / 05$ & $25 / 06$ & $14 / 06$ \\
\hline & Torf:Perlit & $27 / 02$ & $01 / 03$ & $03 / 04$ & $08 / 04$ & $03 / 06$ & $18 / 05$ & $25 / 06$ & $14 / 06$ \\
\hline & Ortalama & $28 / 02$ & $01 / 03$ & $05 / 04$ & $08 / 04$ & $03 / 06$ & $19 / 05$ & $25 / 06$ & $14 / 06$ \\
\hline \multirow{3}{*}{ Yalova İncisi } & Cocopeat & $01 / 03$ & $03 / 03$ & $07 / 04$ & $11 / 04$ & $01 / 06$ & $21 / 05$ & $25 / 06$ & $14 / 06$ \\
\hline & Torf:Perlit & $01 / 03$ & $01 / 03$ & $06 / 04$ & $08 / 04$ & $02 / 06$ & $20 / 05$ & $25 / 06$ & $14 / 06$ \\
\hline & Ortalama & $01 / 03$ & $02 / 03$ & $07 / 04$ & $10 / 04$ & $02 / 06$ & $21 / 05$ & $25 / 06$ & $14 / 06$ \\
\hline \multirow{3}{*}{ Prima } & Cocopeat & $06 / 03$ & $03 / 03$ & $11 / 04$ & $08 / 04$ & $03 / 06$ & $21 / 05$ & $25 / 06$ & $14 / 06$ \\
\hline & Torf:Perlit & $05 / 03$ & $02 / 03$ & $10 / 04$ & $07 / 04$ & $03 / 06$ & $20 / 05$ & $25 / 06$ & $14 / 06$ \\
\hline & Ortalama & $06 / 03$ & $03 / 03$ & $11 / 04$ & $08 / 04$ & $03 / 06$ & $21 / 05$ & $25 / 06$ & $14 / 06$ \\
\hline \multirow{2}{*}{$\begin{array}{l}\text { Ortalama } \\
\text { (Ortam) }\end{array}$} & Cocopeat & $03 / 03$ & $02 / 03$ & $08 / 04$ & $09 / 04$ & $02 / 06$ & $21 / 05$ & $25 / 06$ & $14 / 06$ \\
\hline & Torf:Perlit & $01 / 03$ & $01 / 03$ & $10 / 04$ & $08 / 04$ & $03 / 06$ & $19 / 05$ & $25 / 06$ & $14 / 06$ \\
\hline
\end{tabular}

Tablo 2. Bazı erkenciüzüm çeşitlerinin sürgün uzunluğu, boğums ayısı ve gövde çapıüzerine ortamların etkis i (2014 y1l)

\begin{tabular}{|c|c|c|c|c|}
\hline Çeşit & Ortam & $\begin{array}{l}\text { Sürgün uzunluğu } \\
(\mathrm{cm})^{*}\end{array}$ & $\begin{array}{l}\text { Boğum say1s1 } \\
\text { (adet) }^{*}\end{array}$ & $\begin{array}{c}\text { Gövde çap1 } \\
\text { (mm) }\end{array}$ \\
\hline \multirow{3}{*}{ Trakya İlkeren } & Cocopeat & 168.76 & 35.06 & 6.08 \\
\hline & Torf:Perlit & 196.14 & 37.55 & 5.71 \\
\hline & Ortalama & $182.50 \mathrm{a}$ & $36.30 \mathrm{a}$ & 5.89 \\
\hline \multirow{3}{*}{ Yalova İncisi } & Cocopeat & 142.73 & 32.13 & 6.95 \\
\hline & Torf:Perlit & 136.55 & 30.00 & 6.11 \\
\hline & Ortalama & $139.60 \mathrm{~b}$ & $31.06 \mathrm{~b}$ & 6.53 \\
\hline \multirow{3}{*}{ Prima } & Cocopeat & 159.86 & 35.80 & 6.26 \\
\hline & Torf:Perlit & 170.30 & 37.60 & 6.28 \\
\hline & Ortalama & $165.10 \mathrm{ab}$ & $36.70 \mathrm{a}$ & 6.27 \\
\hline \multirow{2}{*}{ Ortalama (Ortam) } & Cocopeat & 157.12 & 34.33 & 6.42 \\
\hline & Torf:Perlit & 167.66 & 35.05 & 6.03 \\
\hline \multirow{3}{*}{$\mathrm{LSD}_{0.05}$} & Çeşit & 29.30 & 3.33 & O.D. \\
\hline & Ortam & Ö.D. & Ö.D. & Ö.D. \\
\hline & İnteraksiy on & Ö.D. & Ö.D. & Ö.D. \\
\hline
\end{tabular}

*: Aynı sütun içerisinde farklı harflerle gösterilen ortalamalar arasında istatistiki farklılık bulunmaktadır (P<0.05), Ö.D.: Önemli değil

ve ortamlar arasinda istatistiksel anlamda bir farklılık görülmemiştir.

Çeşitlerin üzüm verimi ile salkım ve tane özelliklerine ilişkin bulguların verildiği Tablo 3’ten görüldüğü gibi; 2015 yılında çeşitler, 2016 yılında ise ortamlar arasında verim ve salkım ağırlığ1 bakımından önemli düzeyde farklılık görülmüştür. Buna göre, 2015 yılında en yüksek omca başına üzüm verimi $6731 \mathrm{~g} \mathrm{omca}^{-1}$ ile Prima çeşidi ve $6577 \mathrm{~g}$ omca $^{-1}$ ile Trakya İlkeren çeşidinden elde edilmiştir. Çalışmanın 2016 yılında ise ele alınan çeşitler arasında omca başına üzüm verimi yönünden istatistiksel anlamda farklılık görülmemiş; Yalova İncisi'nden $4357 \mathrm{~g}$ omca $^{-1}$, Prima çeşidinden $4204 \mathrm{~g} \mathrm{omca}^{-1}$ ve Trakya İlkeren' den $3941 \mathrm{~g}$ omca $^{-1}$ üzüm verimi elde edilmiştir. Araştırmada, omca başına üzüm verimi yönünden; 2016 y1lında, Torf:Perlit (1:2) karışımının en yüksek değeri (4865 g omca ${ }^{-1}$ ) verdiğ $i$; istatistiksel anlamda farklılık görülmese de ilk yıl sonuçlarında da benzer bulguların elde edildiği görülmüştür. Trakya İlkeren çeşidi, 2015 yılında en yüksek salkım ağırlığı değerini (506.3 g) vermiştir. Yalova İncisi ve Prima çeşitlerinde salkım ağırlı̆ı sırasıyla 299.2 g ve 309.2 g olmuş ve bunlar istatistiksel olarak ikinci grubu oluşturmuşlardır. Araştırmanın 2016 y1lı sonuçlarına göre, salkım ağırlı̆̆1 yönünden Torf:Perlit (1:2) karışımının daha yüksek değerler verdiği belirlenmiştir (Tablo 3). Üç çeşidin salkım ağırlıkları bakımından sınıf aralığının orta büyüklükte olduğu tespit edilmiştir (Çelik, 2011). TSE 101'e göre Trakya İlkeren çeşidinden ekstra sinıfina, Yalova İncisi ve Prima çeşidinden ise 1. sinıf grubuna giren salkım ağırlıkları elde edilmiştir (Anonim, 2002) (Şekil 1). Çalışmada, 100 tane ağırlı̆̆ yönünden, gerek çeşitler arasında ve gerekse yetiştirilen ortamlar arasında istatistiksel anlamda farklılık görülmemiş; çeşitlerin 100 tane ağırlıklarının 315.27-406.67 g arasında değiştiği belirlenmiştir (Tablo 3). 
Tablo 3. Bazı erkenci üzüm çeşitlerinin üzüm verimi ile salkım ve tane ağırlıkları üzerine farklı ortamların etkisi (2015 ve 2016 y1li)*

\begin{tabular}{|c|c|c|c|c|c|c|c|}
\hline \multirow{2}{*}{ Çeşit } & \multirow{2}{*}{ Ortam } & \multicolumn{2}{|c|}{ Verim $\left(\right.$ g omca $\left.^{-1}\right)$} & \multicolumn{2}{|c|}{ Salkım ağırlığı (g) } & \multicolumn{2}{|c|}{100 tane ağırlığı $(\mathrm{g})$} \\
\hline & & 2015 & 2016 & 2015 & 2016 & 2015 & 2016 \\
\hline \multirow{3}{*}{ Trakya İlkeren } & Cocopeat & 6554 & 2984 & 567.9 & 298.4 & 322.33 & 329.57 \\
\hline & Torf:Perlit & 6600 & 4899 & 444.7 & 489.9 & 331.23 & 387.17 \\
\hline & Ortalama & $6577 \mathrm{a}$ & 3941 & $506.3 \mathrm{a}$ & 394.1 & 326.78 & 358.37 \\
\hline \multirow{3}{*}{ Yalova İncisi } & Cocopeat & 5541 & 3733 & 302.8 & 248.9 & 315.27 & 353.47 \\
\hline & Torf:Perlit & 5584 & 4980 & 295.6 & 332.0 & 328.83 & 362.87 \\
\hline & Ortalama & $5563 \mathrm{~b}$ & 4357 & $299.2 \mathrm{~b}$ & 290.4 & 322.05 & 358.17 \\
\hline \multirow{3}{*}{ Prima } & Cocopeat & 6113 & 3693 & 279.0 & 246.2 & 379.20 & 406.67 \\
\hline & Torf:Perlit & 7348 & 4715 & 339.3 & 314.3 & 385.90 & 376.47 \\
\hline & Ortalama & $6731 \mathrm{a}$ & 4204 & $309.2 \mathrm{~b}$ & 280.3 & 382.55 & 391.57 \\
\hline \multirow{2}{*}{ Ortalama (Ortam) } & Cocopeat & 6069 & $3470 \mathrm{~B}$ & 383.2 & $264.5 \mathrm{~B}$ & 338.93 & 363.23 \\
\hline & Torf:Perlit & 6511 & $4865 \mathrm{~A}$ & 359.9 & $378.7 \mathrm{~A}$ & 348.66 & 375.50 \\
\hline \multirow{3}{*}{$\mathrm{LSD}_{0.05}$} & Çeşit & 662 & O.D. & 72.35 & O.D. & O.D. & O.D. \\
\hline & Ortam & Ö.D. & 812 & Ö.D. & 60.76 & Ö.D. & Ö.D. \\
\hline & İnteraksiy on & Ö.D. & Ö.D. & Ö.D. & Ö.D. & Ö.D. & Ö.D. \\
\hline
\end{tabular}

*: Aynı sütun içerisinde farklı harflerle gösterilen ortalamalar arasında istatistiki farklılık bulunmaktadır (P<0.05), Ö.D.: Önemli deği
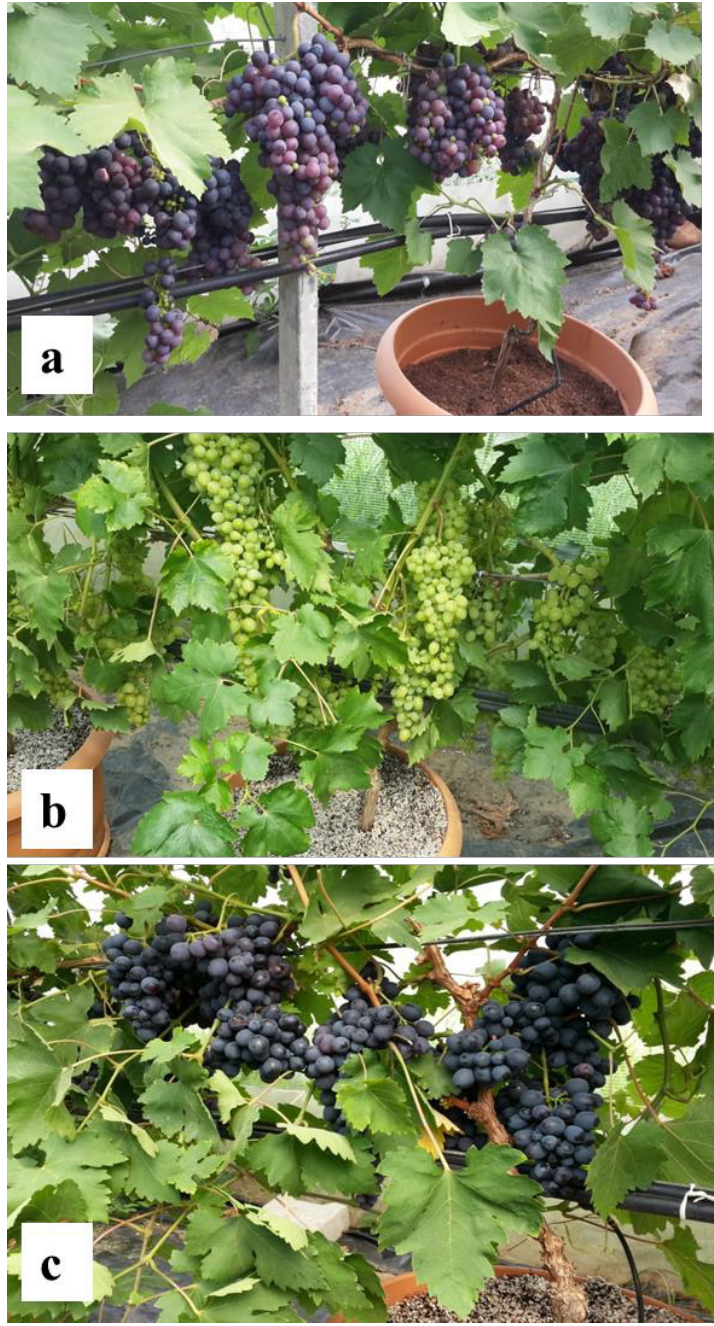

Şekil 1. Topraksızkültür koşullarında yetiştirilen Trakya İlkeren (a) ve Yalova İncisi (b) ile Prima (c) çeşidi omcası ve salkımları
Yapılan istatistiki değerlendirme farklı çeşitlerin ve ortamların, şıra özellikleri üzerine önemli etkide bulunmadığını göstermiştir (Tablo 4). Elde edilen değerler sonucunda, bütün çeşit ve ortamlardan elde edilen üzümlerde yeterli olgunluk indisi düzeylerine ulaşıldığı değerlendirilmiştir. $\mathrm{Bu}$ çalışmada elde edilen olgunluk indisi değerlerinin Adana koşullarında, Tangolar ve ark. (2015) ile Ergenoğlu ve ark. (1999b)'nın; Antalya koşullarında Uzun ve Özbaş (1995) ve Hatay koşullarında Kamiloğlu ve ark. (2011)'nın erkenci çeşitler için derim zamanında buldukları değerlerle uyum içinde olduğu saptanmıştır. Bazı uygulamalardaki değerlerin sofralık üzümler için öngörülen minimum 20/1 olgunluk indisi değerinin (Uzun, 2011) çok üzerinde olduğu dikkati çekmiştir.

Araştırmanın 2. ve 3. yılları (2015 ve 2016) vejetasyon döneminde, tam çiçeklenme ve ben düşme dönemlerinde ölçülen gövde çap1 değerlerine göre (Tablo 5), Yalova İncisi üzüm çeşidi en yüksek değerleri vermiştir.

Deneme alanındaki çeşitlerden ben düşme döneminde alınan yaprak örneklerinde belirlenen makro element içerikleri Tablo 6'da verilmiştir. En yüksek azot değerleri 2015 ve 2016 yillarında Trakya İlkeren (sırasiyla \% 1.95 ve $\%$ çeşidinden elde edilmiş, fosfor değerleri bakımından 2015 yılında çeşitler arasında bir fark oluşmamış; 2016 yllında Yalova İncisi ve Prima is tatistiksel olarak aynı grupta yer alarak en yüks ek değerleri (\% 1.14) vermişlerdir. En yüksek potasyum değeri, 2015 yılında Yalova İncisinde belirlenmiştir. Yaprakların magnezyum içerikleri bakımından farklılığın her iki yılda da önemli olmadığ $1 ; \mathrm{Mg}$ içeriklerinin \% $\quad 0.52-2.53$ arasında değişiklik gösterdiği saptanmıştır (Tablo 6). 
Tablo 4. Bazı erkenciüzüm çeşitlerinin şıra özellikleri üzerine farklı ortamların etkisi (2015 ve 2016 yılı)*

\begin{tabular}{llllllllll}
\hline \multirow{2}{*}{ Çeşit } & \multirow{2}{*}{ Ortam } & \multicolumn{2}{c}{ SÇKM (\%) } & \multicolumn{2}{c}{ Asitlik (\%) } & \multicolumn{2}{c}{$\mathrm{pH}$} & \multicolumn{2}{c}{$\begin{array}{c}\text { Olgunluk indisi } \\
\text { (SÇKM/Asitlik) }\end{array}$} \\
\cline { 3 - 10 } & & 2015 & 2016 & 2015 & 2016 & 2015 & 2016 & 2015 & 2016 \\
\hline \multirow{2}{*}{ Trakya } & Cocopeat & 15.23 & 14.57 & 0.527 & 0.550 & 3.51 & 3.44 & 29.32 & 26.51 \\
İlkeren & Torf:Perlit & 13.30 & 16.53 & 0.518 & 0.542 & 3.37 & 3.51 & 25.72 & 30.55 \\
& Ortalama & 14.27 & $15.55 \mathrm{a}$ & $0.522 \mathrm{a}$ & $0.546 \mathrm{~b}$ & $3.44 \mathrm{~b}$ & $3.47 \mathrm{~b}$ & $27.52 \mathrm{~b}$ & $28.53 \mathrm{~b}$ \\
\hline \multirow{2}{*}{ Yalova } & Cocopeat & 13.53 & 15.77 & 0.278 & 0.354 & 4.12 & 3.96 & 48.68 & 45.26 \\
İncisi & Torf:Perlit & 13.93 & 15.37 & 0.254 & 0.312 & 3.99 & 3.99 & 55.39 & 49.35 \\
& Ortalama & 13.73 & $15.57 \mathrm{a}$ & $0.266 \mathrm{~b}$ & $0.333 \mathrm{c}$ & $4.06 \mathrm{a}$ & $3.97 \mathrm{a}$ & $52.04 \mathrm{a}$ & $47.31 \mathrm{a}$ \\
\hline \multirow{2}{*}{ Prima } & Cocopeat & 13.83 & 13.90 & 0.456 & 0.561 & 3.59 & 3.43 & 30.32 & 24.80 \\
& Torf:Perlit & 12.97 & 13.57 & 0.527 & 0.604 & 3.47 & 3.34 & 26.56 & 22.51 \\
& Ortalama & 13.40 & $13.73 \mathrm{~b}$ & $0.492 \mathrm{~b}$ & $0.583 \mathrm{a}$ & $3.53 \mathrm{~b}$ & $3.39 \mathrm{c}$ & $28.44 \mathrm{~b}$ & $23.66 \mathrm{c}$ \\
\hline Ortalama & Cocopeat & 14.20 & 14.74 & 0.420 & 0.488 & 3.74 & 3.61 & 36.11 & 32.19 \\
(Ortam) & Torf:Perlit & 13.40 & 15.16 & 0.433 & 0.486 & 3.61 & 3.61 & 35.89 & 34.14 \\
\hline \multirow{2}{*}{ LSD 0.05} & Çeşit & O.D. & 1.07 & 0.058 & 0.03 & 0.19 & 0.06 & 7.52 & 4.48 \\
& Ortam & Ö.D. & Ö.D. & Ö.D. & Ö.D. & Ö.D. & Ö.D. & Ö.D. & Ö.D. \\
& İnteraksiyon & Ö.D. & Ö.D. & Ö.D. & Ö.D. & Ö.D. & Ö.D. & Ö.D. & Ö.D. \\
\hline \multirow{2}{*}{ OAn }
\end{tabular}

: Aynı sütun içerisinde farklı harflerle gösterilen ortalamalar arasında istatistiki farklılık bulunmaktadır (P<0.05), Ö.D.: Önemli değil

Tablo 5. Farklı fenolojik dönemler itibariyle çeşitlerin gövde çapı (mm) üzerine ortamların etkisi (2015 ve 2016 y1li) $^{*}$

\begin{tabular}{|c|c|c|c|c|c|}
\hline \multirow{2}{*}{ Çeşit } & \multirow{2}{*}{ Ortam } & \multicolumn{2}{|c|}{ Tam çiçeklenme } & \multicolumn{2}{|c|}{ Ben düşme } \\
\hline & & 2015 & 2016 & 2016 & 2015 \\
\hline \multirow{3}{*}{ Trakya İlkeren } & Cocopeat & 9.72 & 14.76 & 11.94 & 14.94 \\
\hline & Torf:Perlit & 10.98 & 15.78 & 12.74 & 16.38 \\
\hline & Ortalama & $10.35 \mathrm{c}$ & $15.27 \mathrm{~b}$ & $12.34 \mathrm{c}$ & $15.66 \mathrm{~b}$ \\
\hline \multirow{3}{*}{ Yalova İncisi } & Cocopeat & 12.53 & 18.46 & 16.45 & 19.65 \\
\hline & Torf:Perlit & 12.98 & 19.34 & 16.05 & 21.29 \\
\hline & Ortalama & $12.75 \mathrm{a}$ & $18.90 \mathrm{a}$ & $16.25 \mathrm{a}$ & $20.47 \mathrm{a}$ \\
\hline \multirow{3}{*}{ Prima } & Cocopeat & 10.94 & 18.44 & 14.28 & 19.12 \\
\hline & Torf:Perlit & 11.72 & 19.65 & 15.09 & 20.60 \\
\hline & Ortalama & $11.33 \mathrm{~b}$ & $19.05 \mathrm{a}$ & $14.69 \mathrm{~b}$ & $19.86 \mathrm{a}$ \\
\hline \multirow{2}{*}{ Ortalama (Ortam) } & Cocopeat & $11.06 \mathrm{~B}$ & 17.22 & 14.22 & $17.90 \mathrm{~B}$ \\
\hline & Torf:Perlit & $11.89 \mathrm{~A}$ & 18.26 & 14.63 & $19.42 \mathrm{~A}$ \\
\hline \multirow{3}{*}{$\mathrm{LSD}_{0.05}$} & Çeşit & 0.59 & 1.00 & 1.53 & 1.21 \\
\hline & Ortam & 0.48 & Ö.D. & Ö.D. & 0.99 \\
\hline & İnteraksiy on & Ö.D. & Ö.D. & Ö.D. & Ö.D. \\
\hline
\end{tabular}

*: Aynı sütun içerisinde farklı harflerle gösterilen ortalamalar arasında istatistiki farklılık bulunmaktadır $(\mathrm{P}<0.05)$, Ö.D.: Önemli değil

Tablo 6. Ben düşme dönemi alınan yaprak örneklerinin makro (\%) besin elementi içerikleri (2015 ve 2016 y1li)

\begin{tabular}{|c|c|c|c|c|c|c|c|c|c|}
\hline \multirow{2}{*}{ Çeşit } & \multirow{2}{*}{ Ortam } & \multicolumn{2}{|c|}{$\mathrm{N}$} & \multicolumn{2}{|c|}{$\mathrm{P}$} & \multicolumn{2}{|c|}{$\mathrm{K}$} & \multicolumn{2}{|c|}{$\mathrm{Mg}$} \\
\hline & & 2015 & 2016 & 2015 & 2016 & 2015 & 2016 & 2015 & 2016 \\
\hline \multirow{3}{*}{ Trakya İlkeren } & Cocopeat & 2.28 & $1.08 \mathrm{a}$ & 0.91 & 1.08 & 1.41 & 1.07 & 0.59 & 1.81 \\
\hline & Torf:Perlit & 1.62 & $1.15 \mathrm{a}$ & 0.87 & 1.01 & 1.99 & 1.18 & 0.53 & 1.24 \\
\hline & Ortalama & $1.95 \mathrm{a}$ & $1.12 \mathrm{a}$ & 0.89 & $1.04 \mathrm{~b}$ & $1.70 \mathrm{~b}$ & 1.13 & 0.56 & 1.53 \\
\hline \multirow{3}{*}{ Yalova İncisi } & Cocopeat & 1.99 & $1.14 \mathrm{a}$ & 0.74 & 1.19 & 1.67 & 1.13 & 0.56 & 2.53 \\
\hline & Torf:Perlit & 1.53 & $0.97 \mathrm{~b}$ & 1.34 & 1.10 & 2.41 & 1.22 & 0.55 & 1.70 \\
\hline & Ortalama & $1.76 \mathrm{ab}$ & $1.06 \mathrm{a}$ & 1.04 & $1.14 \mathrm{a}$ & $2.04 \mathrm{a}$ & 1.18 & 0.55 & 2.12 \\
\hline \multirow{3}{*}{ Prima } & Cocopeat & 1.65 & $0.91 \mathrm{~b}$ & 0.86 & 1.13 & 1.33 & 1.08 & 0.61 & 1.82 \\
\hline & Torf:Perlit & 1.42 & $0.73 \mathrm{c}$ & 1.16 & 1.15 & 2.20 & 1.07 & 0.52 & 1.85 \\
\hline & Ortalama & $1.54 \mathrm{~b}$ & $0.82 \mathrm{~b}$ & 1.01 & $1.14 \mathrm{a}$ & $1.76 \mathrm{~b}$ & 1.07 & 0.57 & 1.84 \\
\hline \multirow{2}{*}{$\begin{array}{l}\text { Ortalama } \\
\text { (Ortam) }\end{array}$} & Cocopeat & $1.98 \mathrm{~A}$ & $1.05 \mathrm{~A}$ & 0.83 & 1.13 & $1.47 \mathrm{~B}$ & 1.09 & $0.59 \mathrm{~A}$ & 2.05 \\
\hline & Torf:Perlit & $1.52 \mathrm{~B}$ & $0.95 \mathrm{~B}$ & 1.13 & 1.08 & $2.20 \mathrm{~A}$ & 1.16 & $0.53 \mathrm{~B}$ & 1.60 \\
\hline \multirow{3}{*}{$\mathrm{LSD}_{0.05}$} & Çeşit & 0.25 & 0.07 & Ö.D. & 0.05 & 0.13 & Ö.D. & Ö.D. & Ö.D. \\
\hline & Ortam & 0.20 & 0.06 & Ö.D. & Ö.D. & 0.12 & Ö.D. & 0.02 & Ö.D. \\
\hline & İnteraksiy on & Ö.D. & 0.1 & Ö.D. & Ö.D. & Ö.D. & Ö.D. & Ö.D. & Ö.D. \\
\hline
\end{tabular}

\footnotetext{
": Aynı sütun içerisinde farklı harflerle gösterilen ortalamalar arasında istatistiki farklılık bulunmaktadır $(\mathrm{P}<0.05)$, Ö.D.: Önemli değil
} 
Yaprak örneklerinin Tablo 7'de sunulan mikro besin elementi içerikleri incelendiğinde; yaprakların mangan içeriği yönünden sadece 2016 yılı değerlerinin istatistiksel açıdan farklılık gösterdiği ve en yüksek Mn içeriği $50.22 \mathrm{~kg} \mathrm{mg}^{-1}$ ile Yalova İncisi çeşidinde belirlendiği görülmektedir. Demir içeriği bakımından her iki yılda da çeşitler arasında istatistiksel bir fark oluşmamıştır. Çinko elementinde ise 2015 ve 2016 yıllarında benzer sonuçlar elde edilmiş; her iki yılda da Trakya İlkeren çeşidi, Yalova İncisi ve Prima çeşidinden daha yüksek değerler vermiştir (Tablo 7).

Çalışmada saptanan ve Tablo 6 ve Tablo 7'de verilen makro ve mikro element miktarları, konu ile ilgili bazı yayınlarda (Ecevit, 1986; Ecevit ve Kismal1, 1984; Kovancı ve ark., 1984; Tangolar ve Ergenoğlu, 1989; Çelik ve ark., 1998) yeterli miktarda element düzeyleri için verilen veya araştırıcıların saptadığı miktarlar dikkate alınarak değerlendirilmiștir. Bunlara göre, deneme bitkilerinde saptanan $\mathrm{N}, \mathrm{Zn}$ ve Fe miktarları düşük; $P$ ve $M g$ yüksek, $K$ ve $M n$ yeterli seviyede bulunmuştur. $\mathrm{Bu}$ nedenle, nispeten yeterli üzüm miktarı ve kalitesine ulaşılmış olmasına rağmen; daha sonra yapılacak topraksız kültürde sofralık üzüm yetiştiriciliği çalışmalarında, eksikliği görülen azot, çinko ve demir elementleri ile ilgili gübrelemeye önem verilmesinde yarar olduğu kanısına varılmıştır.

Tablo 7. Ben düşme dönemi alınan yaprak örneklerinin mikro $\left(\mathrm{mg} \mathrm{kg}^{-1}\right)$ besin element içerikleri (2015 ve 2016 y11) $)^{*}$

\begin{tabular}{|c|c|c|c|c|c|c|c|}
\hline \multirow{2}{*}{ Çeşit } & \multirow{2}{*}{ Ortam } & \multicolumn{2}{|c|}{$\overline{M n}$} & \multicolumn{2}{|c|}{$\mathrm{Fe}$} & \multicolumn{2}{|c|}{$\mathrm{Zn}$} \\
\hline & & 2015 & 2016 & 2015 & 2016 & 2015 & 2016 \\
\hline \multirow{3}{*}{ Traky a İlkeren } & Cocopeat & 115.08 & 62.16 & 58.31 & 47.50 & 47.78 & 24.91 \\
\hline & Torf:Perlit & 145.88 & 22.62 & 61.49 & 46.16 & 37.01 & 19.08 \\
\hline & Ortalama & 130.48 & $42.39 \mathrm{~b}$ & 59.90 & 46.83 & $42.40 \mathrm{a}$ & $22.00 \mathrm{a}$ \\
\hline \multirow{3}{*}{ Yalova İncisi } & Cocopeat & 184.10 & 73.78 & 55.99 & 48.03 & 29.55 & 14.67 \\
\hline & Torf:Perlit & 167.14 & 26.66 & 74.33 & 44.12 & 30.12 & 14.10 \\
\hline & Ortalama & 175.62 & $50.22 \mathrm{a}$ & 65.16 & 46.08 & $29.83 \mathrm{~b}$ & $14.38 \mathrm{~b}$ \\
\hline \multirow{3}{*}{ Prima } & Cocopeat & 112.27 & 64.06 & 53.31 & 55.70 & 20.61 & 12.35 \\
\hline & Torf:Perlit & 160.58 & 22.65 & 55.09 & 48.14 & 21.03 & 9.94 \\
\hline & Ortalama & 136.43 & $43.35 \mathrm{~b}$ & 54.20 & 51.92 & $20.82 \mathrm{c}$ & $11.14 \mathrm{c}$ \\
\hline \multirow{2}{*}{ Ortalama (Ortam) } & Cocopeat & 137.15 & $66.67 \mathrm{~A}$ & 55.87 & 50.41 & 32.64 & $17.31 \mathrm{~A}$ \\
\hline & Torf:Perlit & 157.87 & $23.98 \mathrm{~B}$ & 63.64 & 46.14 & 29.39 & $14.37 \mathrm{~B}$ \\
\hline \multirow{3}{*}{$\operatorname{LSD}_{0.05}$} & Çeşit & O.D. & 5.47 & O.D. & O.D. & 5.74 & 1.72 \\
\hline & Ortam & Ö.D. & 4.47 & Ö.D. & Ö.D. & Ö.D. & 1.40 \\
\hline & İnteraksiy on & Ö.D. & Ö.D. & Ö.D. & Ö.D. & Ö.D. & Ö.D. \\
\hline
\end{tabular}

": Aynı sütun içerisinde farklı harflerle gösterilen ortalamalar arasında istatistiki farklılık bulunmaktadır $(\mathrm{P}<0.05)$, Ö.D.: Önemli değil

\section{Sonuçlar}

Çalışmadan elde edilen mevcut bulgular genel olarak bu aşamada Prima ve Trakya İlkeren çeşitlerinden birim alana yüksek verim alınabileceğini ve en az açıktaki kadar yüksek kalite düzeyine erişebileceğinin işaretlerini vermiştir. Araştırma koşullarında uygulanan beslenme ve sulama koşullarında denemeye alınan iki yetiştirme ortamının da topraksız kültür üzüm yetiştiriciliği çalışmaları için önerilebileceği ortaya çıkmıştır. Tercih edilmelerinde temin kolaylığı ve maliyetleri en önemli etkenler olacaktır. Üzerinde çalışılan sistemde 850 asma da dikilebileceği mümkün olduğundan 2015 ve 2016 yıllarında sırasıyla, İlkeren çeşidinde 5610 ve $3400 \mathrm{~kg} \mathrm{da}^{-1}$; Prima çeşidinde 6731 ve $4204 \mathrm{~kg} \mathrm{da}^{-1}$, Yalova İncisi çeşidinde ise 4728 ve $3703 \mathrm{~kg} \mathrm{da}^{-1}$ üzüm verimlerine ulaşılabileceği görülmüştür. $\mathrm{Bu}$ değerler, ülkemizde açıta üzüm yetiştiriciliği kapsaminda elde edilen ortalama $900-1000 \mathrm{~kg} \mathrm{da}^{-1}$ verim değerlerinin (Söylemezoğlu ve ark., 2015) oldukça üzerinde değerlerdir.

$\mathrm{Bu}$ nedenle, araştırma sonucunda, sofralık üzüm üretiminin topraksı kültür ortamında başarılması ile seralarda yetiştirilen ürünlere alternatif olarak üzümün de katılabileceği gösterilmiştir.

\section{Teşekkür}

$\mathrm{Bu}$ çalışma, Çukurova Üniversitesi Bilimsel Araştırma Projeleri (BAP) Koordinasyon birimi tarafindan desteklenmiştir (Proje No: FBA-20142494).

\section{Kaynaklar}

Anonim, 2002. Sofralı Üzüm Standardı. Türk Standartları Enstitüsü, No: 112, Ankara. 
Barton, C.J., 1948. Photometric analysis of phosphate rock. Analytical Chemistry, 20(11): 1068-1073.

Buttaro, D., Serio, F., Santamaria, P., 2012. Soilless greenhouse production of table grape under Mediterranean conditions. Journal of Food, Agriculture \& Environment, 10(2): 641-645.

Chapman, H.D., Pratt, P.F., 1961. Methods of Analy sis for Soils, Plants and Waters. University of California, Division of Agricultural Science, Berkeley, California.

Çelik, H., Ağaoğlu, Y.S., Fidan, Y., Marasal1, B., Söylemezoğlu, G., 1998. Genel Bağcllı. Sunfidan A.Ş. Mesleki Kitaplar Serisi 1, Fersa Matbaacıllk Sanayi Ticaret Limited Şirketi, Ankara.

Çelik, S., 2011. Bağcılık (Ampeloloji), Cilt -1. Dağtım: Namık Kemal Üniversitesi, Ziraat Fakültesi, Bahçe Bitkileri Bölümü, Tekirdağ, Basım: Avcı Ofset, İstanbul.

Di Lorenzo, R., Dimauro, B., Guarasci, F., Rinoldo, C., Gambino, C., 2012. Multiple productive cycles in the same year in soilless tablegrape cultivation. 35th World Congress of Vine and Wine, 18-22 June, İzmir, Turkey, p. 20.

Di Lorenzo, R., Gambino, C., Dimauro, B., 2005. Soilless cultivation in the table grape cultivation. Convegno Nazionale "Strategie Per Il Miglioramento Dell'orticoltura Protetta In Sicilia", Scoglitti $(R G)$, 25-26 November, pp. 53-64.

Di Lorenzo, R., Pisciotta, A., Santamaria, P., Scariot, V., 2013. From soil to soil-less in horticulture: Quality and typicity. Italian Journal of Agronomy, 8(4): 255260.

Ecevit, M.F., 1986. R99 Amerikan asma anacı üzerine aşılı bazı üzüm çeşitlerinde mineral besin maddeleri arasındaki ilişkiler üzerinde araştırmalar. Derim, 3(2): 69-76.

Ecevit, M.F., Kısmalı, İ. 1984. Bazı üzüm çeşitlerinin mineral beslenmesine R99 Amerikan asma anacinın etkileri üzerinde araştırmalar. Tokat Bă̆cllı̆ Seтроzуити, 25-28 Ekim, Tokat, s. 135-145.

Ergenoğlu, F., Tangolar, S., Gök, S., 1999a. Perlette ve Uslu üzüm çeşitlerinin Adana ekolojisinde plastik örtüaltında yetiştirilmesi. Türkiye III. Ulusal Bahçe Bitkileri Kongresi, 14-17 Eylül, Ankara, s. 9991003.

Ergenoğlu, F., Tangolar, S., Orhan, E., Gök, S., Büyüktaş, N., 1999b. Bazı sofralık üzüm çeşitlerinin farklı zamanlarda plastik örtüaltına alınmasının verim ve kalite üzerine etkileri. Turkish Journal of Agriculture and Forestry, 23(4): 899-908.

Gül, A., 2012. Topraksız Tarım. Hasad Yayıncılık Ltd. Şti.

Hoagland, D.R., Arnon, D.I., 1950. The water-culture method for growing plants without soil. California Agricultural Experiment Station Circular, 347: 1-32.
Kacar, B., 1995. Bitki ve Toprağn Kimyasal Analizleri, III. Toprak Analizleri. Ankara Üniversitesi, Ziraat Fakültesi, Eğitim, Araştırma ve Geliștirme Vakfi Yay ınları No: 3, Ankara.

Kamiloglu, O., Polat, A.A., Durgac, C., 2011. Comparison of open yield and protected cultivation of five early table grape cultivars under Mediterranean conditions. Turkish Journal of Agriculture and Forestry, 35(5): 491-499.

Kovancı, İ., Atalay, İ.Z., Anaç, D., 1984. Ege Bölgesi Bağlarının Beslenme Durumunun Toprak ve Bitki Analizleri ile İncelenmesi. Bilgehan Basımevi, Bornova-İzmir.

Lees, R., 1971. Laboratory Handbook of Methods of Food Analysis. Leonard Hill Books. London.

Polat, İ., Uzun, H.İ., 2007. Bazı üzüm çeşitlerinin plastik sera ve açık arazide yetiştiriciliğinde erkencilik, verim ve kalite üzerine etkisi. $V$. Ulusal Bahçe Bitkileri Kongresi, 4-7 Eylül, Erzurum, Cilt 2, s. 319-323.

Polat, İ., Özkan, C.F., Kaya, H., Eski, H., 2003. Topraksız kültür üzüm yetiştiriciliğinde farklı ortamların erkencilik, kalite ve verim üzerine etkisi. Türkiye 4. Ulusal Bahçe Bitkileri Kongresi, 08-12 Eylül, Antalya, s. 493-496.

Söylemezoğlu, G., Kunter, B., Akkurt, M., Sağlam, M., Ünal, A., Buzrul, S., Tahmaz, H., 2015. Bağcllı̆̆ın geliştirilmesi yöntemleri ve üretim hedefleri. Türkiye Ziraat Mühendisliği VIII. Teknik Kongresi, 12-16 Ocak, Ankara, s. 606-629.

Tangolar, S., 2011. Örtü Altında Bağcılık. A. Gül (Ed.), Örtüaltı Üretim Sistemleri, Örtüaltında Bağcıllk ve Meyvecilik, Ünite No: 10, Anadolu Üniversitesi Yayınları, No: 2275, Açı Öğretim Fakültesi Yayını No: 1272, Anadolu Üniversitesi Web-Ofset Tesisleri, s. 201-219.

Tangolar, S., Ergenoğlu, F., 1989. Değişik anaçların erkenci bazı üzüm çeşitlerinde yaprakların mineral besin maddesi ve çubukların karbonhidrat içerikleri üzerine etkisi. Doğa Türk Tarım ve Ormancllk Dergisi, 13(3b): 1267-1283.

Tangolar, S., Gök Tangolar, S., Altunöz, D., 2015. Bazı erkenci üzüm çeșitlerinin sabit havalandırma açıklı̆̆na sahip plastik örtü ve kuş net altında erkencilik, verim ve kalite özelliklerinin belirlenmesi. Selçuk Tarım ve Gıda Bilimleri Dergisi-A 27 (Türkiye 8. Bağcılık ve Teknolojileri Sempozyumu Özel Say 1s1), s. 160-169.

Uzun, H.İ., Özbaş, O., 1995. Antalya koşullarında erkencilik sağlamak amacıyla Perlette ve Cardinal üzüm çeşitlerinin plastik örtü altında yetiştirilmesi üzerinde araştırmalar. Türkiye II. Ulusal Bahçe Bitkileri Kongresi, 13-16 Ekim, Adana, s. 452-457.

Uzun, İ., 2011. Bağcılık El Kitabı. Hasad Yayıncılı, İstanbul.

Varış, S., 2012. Ülkemizdeki topraksız kültürün durumu, sorunları ve çözüm önerileri. Tarla Sera, 17: 72-77. 